1 Department of Health Policy, London School of Economics and Political Science, London, UK

2 Usher Institute of Population Health Sciences and Informatics, Edinburgh Medical School, University of Edinburgh, Edinburgh, UK

3 National Hospital Organization Mie Hospital, Tsu, Japan

4 Institute for Population Health, King's College London, London, UK

Correspondence to: K Shimizu k.shimizu1@lse.ac.uk Cite this as: BMJ 2021;373:n962 http://dx.doi.org/10.1136/bmj.n962 Published: 14 April 2021

\title{
Reconsider this summer's Olympic and Paralympic games
}

\author{
Serious questions remain about managing the games safely \\ Kazuki Shimizu, ${ }^{1}$ Devi Sridhar, ${ }^{2}$ Kiyosu Taniguchi, ${ }^{3}$ Kenji Shibuya ${ }^{4}$
}

The government of Japan and the International Olympic Committee are determined to hold the Olympic Games in Tokyo this summer. In February 2021, G7 leaders also supported Japan's commitment to holding the Olympics and Paralympics in Tokyo (Tokyo 2020) "in a safe and secure manner ... as a symbol of global unity in overcoming covid-19."1 While the determination is encouraging, there has been a lack of transparency about the benefits and risk, and international mass gathering events such as Tokyo 2020 are still neither safe nor secure.

The world is still in the middle of a pandemic. SARS-CoV-2 variants are an international concern, causing a resurgence of covid-19 globally. ${ }^{2}$ We must accelerate efforts towards containing and ending the pandemic by maintaining public health and social measures, promoting behaviour change, disseminating vaccines widely, and strengthening health systems. Substantial scientific advancements have occurred over the past year, but vaccine rollout has been inequitable, reducing access in many low and middle income countries. Huge uncertainty remains about the trajectory of the pandemic. ${ }^{3}$

Although a special scheme for vaccinating athletes-marshalled by the International Olympic Committee ${ }^{4}$-may help save lives, it could also encourage vaccine diplomacy, undermine global solidarity (including the Covax global access scheme), and promote vaccine nationalism. Full transparency and clear lines of accountability are critical in any scheme to vaccinate athletes. Furthermore, prioritising athletes over essential workers at high risk in low and middle income countries raises ethical concerns that must be addressed.

\section{Poor control}

Unlike other countries in the Asia-Pacific region, Japan has not yet contained covid-19 transmission. ${ }^{5}$ Despite its poor performance, ${ }^{6}$ Japan still invokes exceptionalism and continues to conceptualise covid-19 within previous planning for pandemic influenza. ${ }^{5}$ The second state of emergency in the Greater Tokyo area was lifted in late March $^{7}$ despite early indications of a resurgence and an increase in covid-19 patients with variants of concern, which have now spread across Japan. ${ }^{89}$

The country's limited testing capacity and sluggish vaccine rollout ${ }^{6}$ have been attributed to lack of political leadership. ${ }^{5}$ Even healthcare workers and other high risk populations will not have access to vaccines before Tokyo 2020, to say nothing of the general population. To properly protect athletes from covid-19, Japan must develop and implement a clear strategy to eliminate community transmission within its borders, ${ }^{5}$ as Australia did before the Australian Open tennis tournament.

Japan and the International Olympic Committee must also agree operational plans based on a robust science and share them with the international community. Waiving quarantine for incoming athletes, officials, broadcasters, press, and marketing partners ${ }^{10}$ risks importing and spreading covid-19 variants of concern. While international spectators will be excluded from the games, ${ }^{11}$ cases could rise across Japan and be exported globally because of increased domestic travel-as encouraged by Japan's official campaigns in 2020..$^{1213}$ Entrants will be asked to download Japan's covid-19 contact tracing app, ${ }^{10}$ but this is known to be unreliable. ${ }^{14}$

The maximum allowable number of domestic spectators is still pending, ${ }^{11}$ but an overwhelmed healthcare system combined with an ineffective test, trace, and isolate scheme $\mathrm{S}^{1213}$ could seriously undermine Japan's ability to manage Tokyo 2020 safely and contain any outbreak caused by mass mobilisation.

Finally, very little has been said officially about the Paralympic games and how to protect the health and rights of people with disabilities during international competition. Current plans lack detail for Paralympic athletes ${ }^{10}$ and may underestimate the risks of covid-19 to people with disabilities.

\section{Safety first}

Plans to hold the Olympic and Paralympic games this summer must be reconsidered as a matter of urgency. The whole global community recognises the need to contain the pandemic and save lives. Holding Tokyo 2020 for domestic political and economic purposesignoring scientific and moral imperatives-is contradictory to Japan's commitment to global health and human security.

Preliminary qualifying competitions for Tokyo 2020 have already been suspended or postponed because of covid-19, and it is now unclear whether equity among athletes can be ensured. ${ }^{15} 16$ We must reconsider this summer's games and instead collaborate internationally to agree a set of global and domestic conditions under which international multisport events can be held in the years ahead. These conditions must embody both Olympic and Paralympic values and adhere to international principles of public health.

Competing interests: We have read and understood BMJ policy on declaration of interests and declare DS is a member of the Scottish Covid-19 Advisory Group and the UK Cabinet Office Covid-19 Advisory Group. KT is a member of the Japanese Covid-19 Advisory Committee on the basic action policy. The views expressed are those of the authors. 
1 Joint statement of G7 leaders. 19 Feb 2021. https://www.g7uk.org/joint-statement-of-g7-leaders19-february-2021/

2 World Health Organization. Coronavirus (covid-19) dashboard. https://covid19.who.int/

3 Skegg D, Gluckman P, Boulton G, etal. Future scenarios for the covid-19 pandemic. Lancet 2021;397:777-8. doi: 10.1016/S0140-6736(21)00424-4. pmid: 33607000

4 International Olympic Committee. Tokyo 2020. IOC lays out progress on vaccinations. $11 \mathrm{Mar}$ 2021. https://www.olympic.org/news/ioc-lays-out-progress-on-vaccinations

5 Shimizu K, Tokuda Y, Shibuya K. Japan should aim to eliminate covid -19. BMJ2021;372:n294. doi: 10.1136/bmj.n294. pmid: 33558342

6 Our World in Data. Statistics and research: coronavirus pandemic (covid-19)-the data. Japan. https://ourworldindata.org/coronavirus-data?country= $\sim$ JPN

7 Japan to lift state of emergency in Tokyo area on Sunday. Nikkei Asia 2021 Mar 17. https://asia.nikkei.com/Spotlight/Coronavirus//apan-to-lift-state-of-emergency-in-Tokyo-area-onSunday

8 Swift R. Japan fears COVID-19 variants are behind possible fourth wave. Reuters 2021 Apr 5.https://www.reuters.com/article/health-coronavirus-japan-strain/japan-fears-covid-19-variantsare-behind-possible-fourth-wave-idUSL4N2LYOL6

9 Ministry of Health. Labour and Welfare, Japan. Responses to COVID-19 (variants), 6 Apr 2021 [in Japanese]. https://www.mhlw.go.jp/content/10900000/000766545.pdf

10 Tokyo 2020. The playbook-athletes and officials. 2021. https://gtimg.tokyo2020.org/image/upload/production/apxdxr1houhj6pbcvto7.pdf

11 Nishizawa K. Tokyo Olympics to bar overseas spectators from postponed games. Bloomberg News 2021 Mar 20. https:/www.bloomberg.com/news/articles/2021-03-20/tokyo-olympics-tobar-overseas-spectators-from-postponed-games

12 Shimizu K, Wharton G, Sakamoto H, Mossialos E. Resurgence of covid-19 in Japan. BMJ 2020;370:m3221. doi: 10.1136/bmj.m3221. pmid: 32816821

13 Shimizu K, Kondo T, Tokuda Y, Shibuya K. An open letter to Japan's new prime minister. Lancet 2020;396:e57. doi: 10.1016/S0140-6736(20)32033-X. pmid: 33002428

14 Japan's COVID-19 app failed to pass on some contact warnings. Reuters 2021 Feb 2. https://www.reuters.com/article/us-health-coronavirus-japan-app-idUSKBN2A31BA

15 Mann RH, Clift BC, Boykoff J, Bekker S. Athletes as community; athletes in community: covid-19, sporting mega-events and athlete health protection. Br J Sports Med 2020;54:1071-2. doi: 10.1136/bjsports-2020-102433. pmid: 32303522

16 International Olympic Committee. Olympic charter-in force as from 17 July 2020. https://stillmedab.olympic.org/media/Document\%20Library/OlympicOrg/General/EN-OlympicCharter.pdf

This article is made freely available for use in accordance with BMJ's website terms and conditions for the duration of the covid-19 pandemic or until otherwise determined by BMJ. You may use, download and print the article for any lawful, non-commercial purpose (including text and data mining) provided that all copyright notices and trade marks are retained. 